\title{
RAPID DETECTION OF BACTERAEMIA BY EARLY SUBCULTURE
}

\author{
Leela A. Ganguli, Wendy O'Hare* and W. A. Hyde
}

\section{Department of Microbiology, Hope Hospital, University of Manchester School of Medicine, Eccles Old Road, Salford M6 $8 H D$}

\begin{abstract}
SUMmary. Inspection and blind subculture was carried out on 7031 consecutive blood cultures at 10 p.m. on the day they were received. Analysis of the results after a 2-year period showed that 119 out of 237 $(50 \%)$ bacteraemic patients were detected at this stage. Preliminary sensitivity tests were done at this time and their results were available within $24 \mathrm{~h}$ of the blood cultures being received. Thus earlier specific therapy was possible in $50 \%$ of the cases of bacteraemia.
\end{abstract}

\section{INTRODUCTION}

The rapid detection, identification and antibiotic susceptibility testing of bacteria from blood cultures is of utmost importance in the successful management of the septicaemic patient (Tilton, 1982). However, the optimum time for routine subculture is still debated. Most laboratories routinely subculture after incubation for 1 day (in practice, 16-24 h) so that the earliest positive results are confirmed on solid media $48 \mathrm{~h}$ after collection. Our evaluation of 'blind' early subculture, in the absence of visible evidence of microbial growth, was prompted by a recent American report that this procedure could yield positive results up to $24 \mathrm{~h}$ earlier than conventional methods (Sliva and Washington, 1980). In our prospective study we have analysed the results of all routine blood cultures examined during a 2 -year period in a diagnostic laboratory.

\section{MATERIALS AND METHODS}

Culture Media. The following blood culture media were used in $125-\mathrm{ml}$ medical flat bottles. (i) The aerobic medium consisted of a bi-phasic medium with $35 \mathrm{ml}$ of Columbia Agar (Lab M, Salford) as the solid phase and $45 \mathrm{ml}$ of Brain Heart Infusion broth (Lab M), containing polyanethol sulphonate (Liquoid, Roche) $0.025 \%$ and thymidine $(\mathrm{BDH}) 0.4 \%$, as the liquid phase. The solid phase was inoculated daily by tilting the bottle so that the broth ran over the slope. Bottles were only opened if there was evidence of growth in that bottle or in the accompanying anaerobic medium. (ii) Following a previous investigation, the anaerobic medium used routinely was Fastidious Anaerobe Broth (FAB; Lab M), a medium supplied commercially (Ganguli, Turton and Tillotson, 1982). Each bottle was inoculated with 3-5 ml of blood. Blood cultures taken after normal working hours were placed in an incubator within easy access for junior doctors and transported to the laboratory the following morning. The same procedures were followed during weekends and holidays.

Received 30 Aug. 1983; accepted 1 Dec. 1983.

* Present address: Royal Manchester Children's Hospital Pendlebury, Manchester. 
Subcultures. Blood cultures taken after laboratory hours were examined visually the following morning. Cultures showing evidence of growth of bacteria, e.g., turbidity or haemolysis, were examined further by Gram's stain and subculture. Bottles that were visually negative at this time and all cultures received during that day (Day l) were inspected at 10 p.m. and the FAB anaerobic bottle was also routinely subcultured at this time (5-13-h incubation). Further routine subcultures were done from the FAB bottle on Day 4 and both bottles were finally opened and subcultured after incubation for 7 days. Bottles were examined visually every day.

Subcultures were done in a Class II Safety Cabinet (Microflow) with sterile disposable plastic loops of $10-\mu$ l volume (NUNC, Denmark). Half plates of blood agar (Columbia; Lab M), blood agar with menadione $0.001 \%$ and haemin $0.005 \%$, and heated blood agar were inoculated at each subculture. Cultures on blood agar were incubated in air, cultures on blood agar with menadione and haemin were incubated anaerobically with $10 \% \mathrm{CO}_{2}$ (Raven Anaerobic Cabinet, Forma Scientific, OH, USA) and cultures on heated blood agar were incubated in air with $5 \%$ $\mathrm{CO}_{2}$. The heated-blood-agar plates used for subculture contained $\mathrm{FAB}$ as a base since work in this Department has shown that this modification allowed the isolation of pyridoxal-independent streptococci (Tillotson, 1981). All plates were examined after incubation for 24 and $48 \mathrm{~h}$. The use of an anaerobic cabinet avoided interruption of anaerobic growth at this stage.

Positive Cultures. The medical laboratory scientific officer (MLSO) was instructed to contact a senior member of the laboratory medical staff when positive blood cultures were first detected by microscopy during the day or at 10 p.m., including weekends. The clinical significance of positive cultures was thus determined by a combination of the numbers of blood cultures found positive from a patient and by discussion between the laboratory medical staff and clinical colleagues. Advice on the choice and dosage of antibiotic therapy was also offered at this time.

TABLE I

Blood cultures examined and time taken to detect bacteraemia

\begin{tabular}{|c|c|c|c|}
\hline & \multicolumn{3}{|c|}{ Number $(\%)$ of cultures in } \\
\hline & $\begin{array}{l}\text { First } \\
\text { year }\end{array}$ & $\begin{array}{l}\text { Second } \\
\text { year }\end{array}$ & Total \\
\hline Total blood cultures & 3282 & 3749 & 7031 \\
\hline $\begin{array}{l}\text { Significant positive } \\
\text { cultures }\end{array}$ & $194(6)$ & $216(6)$ & $410(6)$ \\
\hline $\begin{array}{l}\text { Transient bacteraemias } \\
\text { of doubtful significance } \\
\text { or contaminated }\end{array}$ & $472(14)$ & $389(10)$ & $861(12)$ \\
\hline $\begin{array}{l}\text { Number of patients } \\
\text { examined }\end{array}$ & 1515 & 1656 & 3171 \\
\hline $\begin{array}{l}\text { Number with significant } \\
\text { bacteraemia }\end{array}$ & $117(8)$ & $120(7)$ & $237(8)$ \\
\hline $\begin{array}{l}\text { Detected by } \\
\text { inspection }(\leqslant 13 \mathrm{~h})\end{array}$ & $16(14)$ & $23(19)$ & $39(17)$ \\
\hline $\begin{array}{l}\text { Detected following } \\
\text { blind subculture } \\
\text { ( } \leqslant 13 \mathrm{~h} \text { incub.) }\end{array}$ & $48(41)$ & $32(27)$ & $80(34)$ \\
\hline $\begin{array}{l}\text { Total detected, on solid } \\
\text { medium, within } 24 \mathrm{~h}\end{array}$ & $64(55)$ & $55(46)$ & $119(50)$ \\
\hline $\begin{array}{l}\text { Additional positives } \\
\text { detected by inspecting } \\
\text { next day }(\leqslant 24 \mathrm{~h})\end{array}$ & $14(12)$ & $34(28)$ & $48(20)$ \\
\hline $\begin{array}{l}\text { Total cases reported } \\
\text { positive within } 24 \mathrm{~h}\end{array}$ & $78(67)$ & $89(74)$ & $167(71)$ \\
\hline
\end{tabular}




\section{RESULTS}

From a total of 7031 blood cultures from 3171 patients in a 2-year period (table I), 410 cultures $(6 \%)$ were found to be positive and clinically significant. These cultures were obtained from 237 bacteraemic patients. Of these 237 patients, $39(17 \%)$ had bacteraemia detected by visual and microscopic examination at $10 \mathrm{p} . \mathrm{m}$. on the same day ( $\leqslant 13-h$ incubation) and reported by telephone at that time. Blood cultures from a further $80(34 \%)$ patients were found to be positive when plates from the blind subculture were examined the following morning. Thus, a total of $119(50 \%)$ were

TABLE II

Time taken to detect bacteraemias due to individual micro-organisms

\begin{tabular}{|c|c|c|c|c|c|c|c|c|}
\hline \multirow[b]{2}{*}{ Organism } & \multicolumn{8}{|c|}{$\begin{array}{l}\text { Number of bacteraemias first detected by } \\
\text { inspection or subculture on Day }\end{array}$} \\
\hline & 1 & 2 & 3 & 4 & 5 & 6 & $7 \& 8$ & Total \\
\hline Escherichia coli $\dagger$ & 15 & $27(17)^{*}$ & 9 & 3 & & & & 54 \\
\hline Klebsiella aerogenes & 4 & $5(3)$ & & 1 & & & & 10 \\
\hline Klebsiella oxytoca & 0 & $4(4)$ & 1 & & & & & 5 \\
\hline Enterobacter cloacae & 0 & $3(2)$ & & & & & & \\
\hline Enterobacter aerogenes & 0 & $1(1)$ & & & & & & 1 \\
\hline Enterobacter sakazaki & 1 & & & & & & & 1 \\
\hline Enterobacter agglomerans & 1 & $1(1)$ & & & & & & 2 \\
\hline Serratia spp. & 1 & $5(3)$ & 2 & & & & & 8 \\
\hline Proteus mirabilist + & 2 & $7(3)$ & 1 & 1 & & & & $\begin{array}{r}11 \\
2\end{array}$ \\
\hline Providencia stuarti & & & 1 & & & & & 1 \\
\hline Salmonella typhimurium & 0 & $3(2)$ & & & & & & 3 \\
\hline Salmonella virchow & & & 1 & & & & & 1 \\
\hline Pseudomonas aeruginosa & & & 2 & & & & & 2 \\
\hline Pseudomonas cepacia & & & 1 & & & & & 1 \\
\hline Aeromonas hydrophila & 0 & $1(1)$ & & & & & & 1 \\
\hline Neisseria gonorrhoeae & & & & 1 & 1 & & & \\
\hline Neisseria meningitidis & & & 1 & & & & & 1 \\
\hline Haemophilus influenzae & & & & 1 & & & & 1 \\
\hline Staphylococcus aureus & 8 & $22(9)$ & 8 & 2 & 2 & & & 42 \\
\hline Staphylococcus epidermidis & 0 & $3(3)$ & 3 & 2 & & & & 8 \\
\hline Streptococcus pneumoniae & 3 & 23 (14) & 2 & 3 & 1 & & & 32 \\
\hline Streptococcus sp. Lancefield grp A & & $2(2)$ & 2 & & & & & 4 \\
\hline Streptococcus sp. Lancefield grp B & & $1(1)$ & & & 1 & & & 2 \\
\hline Streptococcus sp. Lancefield grp D & 1 & $6(5)$ & & & & & & 7 \\
\hline Streptococcus milleri & & $3(3)$ & 1 & 2 & & & & 6 \\
\hline Streptococcus mitior & & & 1 & & & & & 1 \\
\hline Streptococcus sangius & & $1(1)$ & & & & & & 1 \\
\hline Streptococcus salivarius & & & 1 & & & & & 1 \\
\hline Streptococcus bovis type 1 & & $2(2)$ & & & & & & 2 \\
\hline Streptococcus sp. (not typed) & & 1 & & & & & & 1 \\
\hline Listeria monocytogenes & & $1(1)$ & & & & & & 1 \\
\hline Clostridium perfringens & 1 & $1(1)$ & 1 & 1 & & & & 4 \\
\hline Bacteroides fragilis & & $2(1)$ & 5 & 1 & & 1 & & 9 \\
\hline ‘Polymicrobial’ $\dagger \dagger$ & & 1 & & & & & & 1 \\
\hline Corynebacterium sp. & & 1 & & & & & & 1 \\
\hline Candidia albicans & & 1 & 1 & 2 & & & & 4 \\
\hline Total & 39 & $128(80)$ & 44 & 20 & 5 & 1 & 0 & 237 \\
\hline
\end{tabular}

* ( ) = bacteraemias detected from blind initial subculture of FAB on Day 1, and included in positives detected on Day 2.

$\dagger$ Two cultures mixed with $B$. fragilis.

$\ddagger$ One culture mixed with $B$. fragilis.

$\dagger \dagger$ Mixed growth of Bacteroides thetaiotaomicron, Peptococcus sp., Streptococcus milleri, Actinomyces viscosus. 
positive on a solid medium, 39 with primary sensitivity test results, within $24 \mathrm{~h}$. Routine visual examination of the bottles on Day 2 enabled a further 48 to be detected by Gram's stain bringing the total number of positive results to $167(71 \%)$ in the first 24 h. The figures for the two 12-month periods were similar. When the bottles that were shown to be positive after 'blind' subculture were re-examined visually the following morning, several did not even then show evidence of growth. This was particularly noted with streptococci and with some anaerobes that do not cause early turbidity in broth culture.

Details of the organisms isolated from 237 bacteraemic patients in the 2 years and the time of their first detection and reporting are shown in table II. The early inspection and subculture at 10 p.m. (bottles incubated 5-13 h) enabled us to report, with preliminary sensitivity test results, 32 out of 54 Escherichia coli, 17 out of 32 Streptococcus pneumoniae and 17 out of 42 Staphylococcus aureus infections within 24 $\mathrm{h}$. Infections with anaerobes or Candida spp. were, however, generally detected after incubation for 48 or $72 \mathrm{~h}$.

\section{Discussion}

It is widely recommended that routine aerobic subculture of incubated blood cultures should be done 1 or 2 days after collection (Bartlett, Ellner and Washington, 1974; Shanson, 1978). American studies have previously demonstrated the value of an earlier routine subculture done on the same day that the culture is taken. Todd and Roe (1975) detected $85 \%$ of their clinically-significant positive cultures by subculturing between 4 and $14 \mathrm{~h}$ after collection. Harkness et al. (1975) detected $48 \%$ of 128 positive cultures after subculture between 3 and $19.5 \mathrm{~h}$ (mean $9.5 \mathrm{~h}$ ) after collection. Sliva and Washington (1980) compared the value of subculturing after incubation for 1-6 h, 6-12 h and 12-17 h. Only $10 \%$ of isolates were detected when subcultured within $6 \mathrm{~h}$ but $36 \%$ (127 out of 350 blood cultures) were positive after $6-12 \mathrm{~h}$ and $63 \%$ ( 114 out of 181 blood cultures) were positive after incubation for $12-17 \mathrm{~h}$. The latter workers recommended that routine subcultures should be performed between 6 and 17 $\mathrm{h}$ after blood collection. The British viewpoint was, however, expressed by Shanson (1978) who recommended that routine subcultures be performed after incubation for 1,2 and 7 days; subculturing within the first $12 \mathrm{~h}$ was not considered of proven value. A prospective comparison of early routine subculture with conventional subculture would prove the benefit of our method beyond doubt. This is impractical because of the large volume of blood required-approximately $60 \mathrm{ml}$ from each patient, the majority of whom are elderly and quite ill.

In the present study an early examination and routine subculture on the same day enabled us to detect, in the first and second years respectively, 64 out of $117(55 \%)$ and 55 out of $120(46 \%)$ bacteraemic patients within $24 \mathrm{~h}$. Early subculture allows preliminary identification and sensitivity tests to be performed within this initial period, thus making earlier specific therapy possible. It also permits rapid detection of 'polymicrobial' septicaemia which again has an important bearing upon therapy.

The additional cost of this system is that of one "call out" for an MLSO after normal laboratory hours, currently $£ 7.97$, a day. It also requires a senior member of the laboratory medical staff to be available for discussion of the clinical significance of the findings with colleagues from the ward. The long range ( 25 miles) radio call system 
currently in operation meets this need without undue loss of mobility and freedom. An examination of contamination rates during the period of this investigation when compared with earlier periods did not reveal any increase due to this procedure. We, therefore, strongly recommend early subculture as an essential part in any diagnostic blood culture system.

We wish to thank Professor J.G. Collee, University of Edinburgh and Professor S. Selwyn, University of London, for their encouragement and helpful comments in the preparation of this paper.

\section{REFERENCES}

Bartlett R C, Ellner P D, Washington J A 1974 Blood Cultures. In: Sherris J C (ed) Cumitech I, American Society for Microbiology, Washington DC. pp 1-6.

Ganguli L A, Turton L J, Tillotson G S 1982 Evaluation of Fastidious Anaerobe Broth as a blood culture medium. Journal of Clinical Pathology 35:458-461.

Harkness J L, Hall M, Ilstrup D M, Washington J A 1975 Effects of atmosphere of incubation and of routine subcultures on detection of bacteremia in vacuum blood culture bottles. Journal of Clinical Microbiology 2:296-299.

Shanson D C 1978 Blood culture techniques. In: Williams J D (ed) Modern topics in infection, Heinemann, London. pp 14-30.

Sliva H S, Washington J A 1980 Optimal time for routine early subculture of blood cultures. Journal of Clinical Microbiology 12:445-446.

Tillotson G S 1981 Evaluation of ten commercial blood culture systems to isolate a pyridoxal-dependent streptococcus. Journal of Clinical Pathology 34:930-934.

Tilton R C 1982 The laboratory approach to the detection of bacteremia. Annual Reviews of Microbiology 36:467-493.

Todd J K, Roe M H 1975 Rapid detection of bacteremia by an early subculture technique. American Journal of Clinical Pathology 64:694-699. 